\title{
Intermittent Explosive Disorder
}

National Cancer Institute

\section{Source}

National Cancer Institute. Intermittent Explosive Disorder. NCI Thesaurus. Code C94332.

A disorder characterized by recurrent episodes of serious assaultive acts or destruction of property due to a failure to resist aggressive impulses; the degree of aggression during these episodes is grossly out of proportion to any psychosocial provocation. The aggressive episodes are not etiologically linked to another mental disorder, a general medical condition, or substance use. 